\title{
MASS TRANSFER PROPERTIES OF Acacia mangium PLANTATION WOOD
}

\author{
Ha Tien Manh ${ }^{1, \star}$ \\ https://orcid.org/0000-0002-8983-9261 \\ Adam L. Redman ${ }^{2}$ \\ https://orcid.org/0000-0001-6573-1574 \\ Chuong Pham Van \\ https://orcid.org/0000-0002-4626-5608 \\ Bui Duy Ngoc ${ }^{1}$ \\ https://orcid.org/0000-0002-2049-8817
}

\begin{abstract}
This study investigated the mass transfer properties (permeability and mass diffusivity) in the longitudinal,radialandtangentialdirectionsof plantation-grownAcaciamangium inVinhPhucprovince,northeast, Vietnam. These properties will be used to complement a conventional drying model in the future. Measurements of gas and liquid permeability were performed using a Porometer (POROLUX ${ }^{\mathrm{TM}} 1000$ ). Mass diffusivity was determined in a constant humidity and temperature chamber using PVC-CHA vaporimeters. Results showed the gas permeability was significant higher than liquid with the descending order of longitudinal, radial, and tangential directions. The permeability anisotropy ratios from the longitudinal to transverse directions of Acacia mangium were much lower than other published species. However, the obvious anisotropy ratios from radial to tangential for both permeability and diffusivity, is one of concerns as they can exacerbate defects during drying. Besides, the high permeability and diffusivity of Acaciamangium compared to some other species reported compounds its relatively fast drying rate.
\end{abstract}

Keywords: Acacia mangium, anisotropy, diffusivity, mass transfer, permeability.

\section{INTRODUCTION}

Vietnam has a large expanding area of plantation forests for over 30 years and the majority of plantation species harvested are acacias. In 1992, 7,2\% of the 913466 ha of planted forest area were acacia species: Acacia auriculiformis (43110 ha) and Acacia mangium (23021 ha) (De Jong et al. 2006). In 2013, the planted forest area increased by 3,89 times, reaching 3556294 ha (Tuan 2014). Among them, the acacia plantation area is about 1,1 million ha $(31 \%)$, with 600000 ha of $A$. mangium, mainly in the north, 400000 ha of clonal acacia hybrid (A. mangium $\times$ auriculiformis), 90000 ha of $A$. auriculiformis, and 5000 ha of $A$. crassicarpa (Harwood and Nambiar 2014). In 2019, the planted forest area was 4316786 ha, of which the acacia species area still constitute a large proportion (Tuan 2020).

${ }^{1}$ Research Institute of Forest Industries, Vietnamese Academy of Forest Sciences, BacTuLiem, Hanoi, Vietnam.

${ }^{2}$ Queensland Department of Agriculture and Fisheries, Horticulture and Forestry Science, Salisbury Research Facility, Salisbury,

Queensland, Australia.

${ }^{3}$ Vietnam National University of Forestry, Xuan Mai, Chuong My, Hanoi, Vietnam.

•Corresponding author: hatienmanhfsiv@gmail.com

Received: 02.06.2020 Accepted: 20.09.2021 
In Vietnam, the export turnover of raw wood goods, especially chips, logs, and sawn timber makes a large proportion of total wood products. In 2018, the export value was 2,19 billion US dollars, accounting for $28,8 \%$ of total export turnovers of wood and wood products. Meanwhile logs and sawn timber materials are imported to provide companies for further processing. Transforming the harvesting structure of plantations from young timber to large timber to supply raw materials for the processing industry to raise the added value of planted forest timber has been an important orientation of the government and forestry departments.

In order to create high quality products from wood, wood drying is an important and mandatory stage in the manufacturing process. There are various methods to perform the drying process including conventional kilns, direct or indirect heating kilns, dehumidifier kilns, solar kilns, microwave drying units, and vacuum kilns (Phonetip 2018). These drying methods requireto control the occurrence of defects during the drying process. This means maintaining a balance between the rate of evaporation of surface moisture and the rate of moisture movement from the interior to the surface of the wood. An effective solution is to use an optimized drying schedule in controlling temperature, relative humidity and airflow under atmospheric pressure (Redman et al. 2017).

The use of mathematical models to optimize the wood drying process is considered by many researchers to be a reliable and cost-effective solution since it does not require spending a lot of time and money on experimental drying batches. A mathematical model can be used to understand and predict drying time and wood quality (Haque 2002). In addition, an accurate mathematical model will be effectively used to evaluate the effect of drying regimes on the drying behavior of wood (Yuniarti et al. 2018).

To optimize the drying process using a mathematical model, a good understanding of the wood and its drying behavior is required (Redman et al. 2017). Several wood properties need to be measured to provide data for developing an accurate drying model. In particular, permeability and water-vapour diffusivity are the key parameters of mass transfer data of the drying model (Redman et al. 2012).

This paper provides results on the measurement of the gas and liquid permeability, which determine mass flow due to the pressure difference; and the water-vapour diffusivity, which determine mass flow due to the concentration difference, of $A$. mangium to provide input data for later drying model.

\section{MATERIALS AND METHODS}

\section{Materials}

The material used for the study, 9-year old A.mangiumlogs, was harvested in Ngoc Thanh Commune, Phuc Yen City, VinhPhuc Province, Vietnam. Each log was sawn into boards with dimensions $1000 \mathrm{~mm}$ x $80 \mathrm{~mm}$ x $27 \mathrm{~mm}$ (L, W, T dimensions). These 200 defect-free boards were selected to dry together from $50 \%$ to 20 $\%$ moisture content during 50 days in a batch of solar kiln located at the Research Institute of Forest Industries, Vietnamese Academy of Forest Sciences, Hanoi, Vietnam. The temperature and relative humidity (RH) of this drying batch depend on weather. The temperature was highest on clear sunny day $\left(48^{\circ} \mathrm{C}\right)$ and lowest at the night $\left(15^{\circ} \mathrm{C}\right)$ and the RH was $73 \%$ and $98 \%$ respectively. The air flow was $2 \mathrm{~m} / \mathrm{s}$.

Among them, 10 defect-free boards ( 5 quarter-sawn and 5 back-sawn boards) with dimensions $300 \mathrm{~mm}$ x $75 \mathrm{~mm}$ x $25 \mathrm{~mm}$ (L, R, T and L, T, R orientations, respectively) were prepared to transport to Salisbury Research Facility, Department of Agriculture and Fisheries, Queensland, Australia, for mass transfer properties investigation. These 10 boards were then sawn into three sections (Figure 1). From the end of the boards, a 70 $\mathrm{mm}$ long sawn section was removed and a pair of $23 \mathrm{~mm}$ diameter cylinders were cored through the surface using a $28 \mathrm{~mm}$ hole-saw.Each core was cut into two equal thickness pieces using a band-saw and was router planed to $10 \mathrm{~mm}$ thickness, to produce 20 tangential and 20 radial permeability samples (right side of the diagram). Sixty longitudinal permeability and 20 longitudinal diffusivity samples were taken along the grain from these sections. The dimensions and preparation of longitudinal permeability samples were same as those used to determine transverse permeability. The longitudinal diffusivity samples were $19 \mathrm{~mm}$ in diameter and 17 $\mathrm{mm}$ in long cylinders. Those were cored using a $24 \mathrm{~mm}$ hole-saw, cut by a band-saw, and router planed. All of permeability samples were divided into 2 equal numbers to determine gas and liquid permeability. Each 80 $\mathrm{mm}$ long sawn section on the left side of the diagram was cored through the surface using a $79 \mathrm{~mm}$ diameter hole-saw and was cut using a band-saw to get 2 equal thickness, $74 \mathrm{~mm}$ diameter cylinders. Afterwards, these cylinders were router planed to $8 \mathrm{~mm}$ thickness to produce 10 radial and 10 tangential (in thickness direction) 
samples for determining transverse diffusivity. The side surfaces of all specimens were coated with two layers of epoxy resin to guarantee the air tightness of the lateral surfaces during measurement.In order to create a fresh flow throughsurface, these specimenswere cleaned by air at pressure of 7 bar. The samples used for gas permeability were equalized in a conditioning chamber at $65 \% \pm 2 \%$ relative humidity and $20^{\circ} \mathrm{C} \pm 0,1^{\circ} \mathrm{C}$ temperature to produce equilibrium conditions of $12 \%$ moisture content. The diffusivity samples were equalized in another conditional chamber at $75 \% \pm 2 \%$ relative humidity and $35^{\circ} \mathrm{C} \pm 0,1{ }^{\circ} \mathrm{C}$ temperature to meet $14 \%$ moisture content.

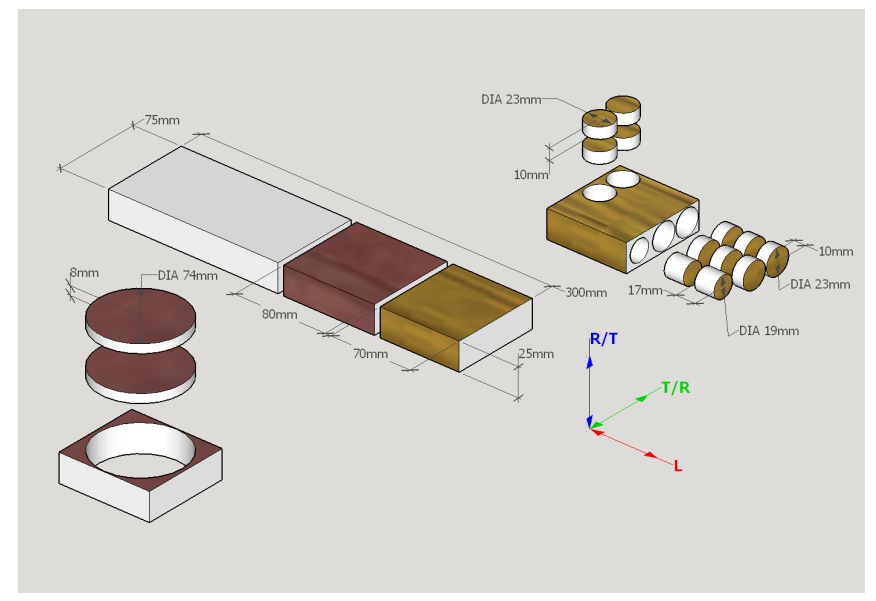

Figure 1: Sample preparation for permeability and diffusivity tests: foreground - longitudinal (L) sampling, background - radial (R), and tangential (T) sampling.

\section{Methods}

\section{Permeability}

Permeability is the property of a material that indicates the ability of free fluids (gas and liquid) to flow through them in response to a pressure gradient (Milota et al. 1995, Leggate et al. 2019). In previous studies, gas and liquid permeability was measured by the rate of permeating flow of fluid through a wood specimen of known length and cross-sectional area while a known pressure difference was applied across it (Booker 1977, Leggate et al. 2019). It was calculated manually via the Equation 1 by Darcy's law (Redman et al. 2012):

$$
K=\frac{Q \mu e P}{A \Delta P \bar{P}}
$$

In which

$K$ is the intrinsic permeability $\left(\mathrm{m}^{2}\right)$

$Q$ is the fluid flux $\left(\mathrm{m}^{3} \cdot \mathrm{s}^{-1}\right)$

$\mu$ is the dynamic viscosity of fluid (Pas)

$e$ is the sample thickness $(\mathrm{m})$

$P$ is the pressure at which flux $Q$ is measured $(\mathrm{Pa})$

$A$ is the sample area $\left(\mathrm{m}^{2}\right)$

$\Delta \mathrm{P}=P_{2}-P_{1}$ is pressure difference between the fluid outlet $\left(P_{2}\right)$ and inlet $\left(P_{1}\right)$ sides of the sample $(\mathrm{Pa})$ 


$$
\bar{P}=\left(P_{1}+P_{2}\right) / 2 \text { is the averaged pressure inside the sample }(\mathrm{Pa}) .
$$

In the present study, all measurements and calculations for all three directions permeability (longitudinal, radial and tangential) were carried out automatically on a Porolux 1000 Porometer (IB-FT GmbH, Berlin, Germany) (Figure 2 ) with control software. Two types of medium for permeability determination were gas (atmospheric air) and liquid (rain-water). For gas, atmospheric air pressure was increased to 4200 mbar. The gas permeability was measured at a pressure difference within this range. For liquid, rain-water pressure was increased and maintained at $2000 \mathrm{mbar}$ for $0,5 \mathrm{~min}$ to measure the longitudinal permeability and at $4500 \mathrm{mbar}$ for $30 \mathrm{~min}$ to measure the transverse permeability. Due to the low permeability encountered for transverse samples (no permeability values could be measured in the transverse direction), the pressure and measurement time were increased. Since temperature influences gas and liquid viscosity, it was taken into account during permeability calculations. The sample thickness was measured at three positions and then averaged to enter into the software along with ambient temperature before running tests. The 298,6 $\mathrm{mm}^{2}$ sample area was a constant because all measurements used the same SH25 sample holder (Figure 3).

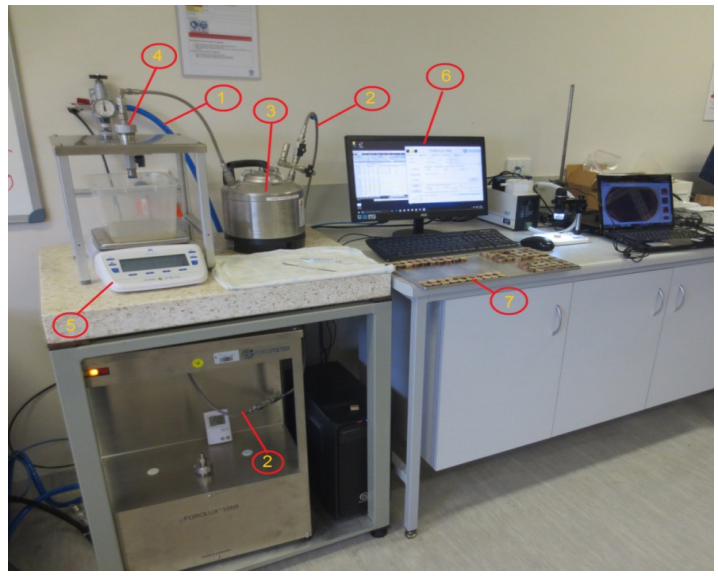

Figure 2: Photo of thePorolux 1000 Porometer used forpermeability test: input of atmospheric air (1) to system at pressure of 7 bar, air pressure line (2) is from system to water tank (3) to apply water to the sample holder (4) in liquid permeability test or to the sample holder directly in gas permeability tests, balance (5) for water output weight connected to the computer, monitor (6) shows parameters and results of the measurement process, and the samples (7).
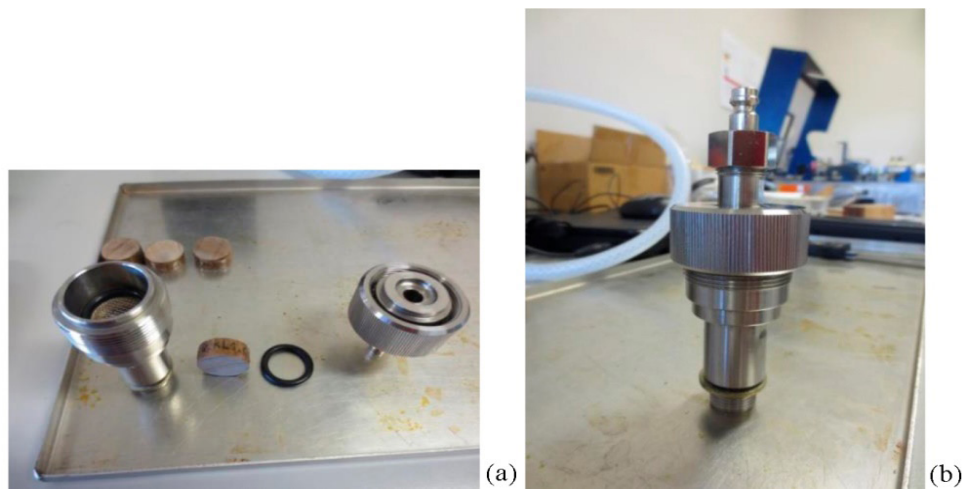

Figure 3: Photo of theSH25 sample holder: (a) Integral parts and (b) assembled holder.

\section{Water-vapour diffusivity}

Two commonly used methods for measuring diffusion coefficients are steady-state and unsteady-state which have different advantages and disadvantages. However, effects of vapour flow out of the sample surface in the steady-state measurement and the sample being exposed to the outside environment in the unsteady-statemeasurement should be eliminated (Perré and Turner 2007). To avoid complexity in this study, the steady-state method was used. The principle of measurement in the steady-state regime is based on the relationship between the partial pressure of vapour and the relative humidity at a fixed temperature. If two surfaces 
of a wood sample are exposed to two different relative humidity levels, the difference in vapour pressure happens. This is the driving force of the diffusive flux through the sample (Zohoun et al. 2003). The mass adsorbed or desorbed is weighed by the sample at chosen time intervals during the experiment to calculate the diffusion coefficient (Tagne et al. 2016).

In this study, the steady-state determination of water-vapour diffusivity was chosen and the technique of the vaporimeter was used (Figure4). These experiments were performed on a vaporimeter that based on the PVC-CHA system developed by the team at AgroParisTech, France as described by Redman et al. (2012).

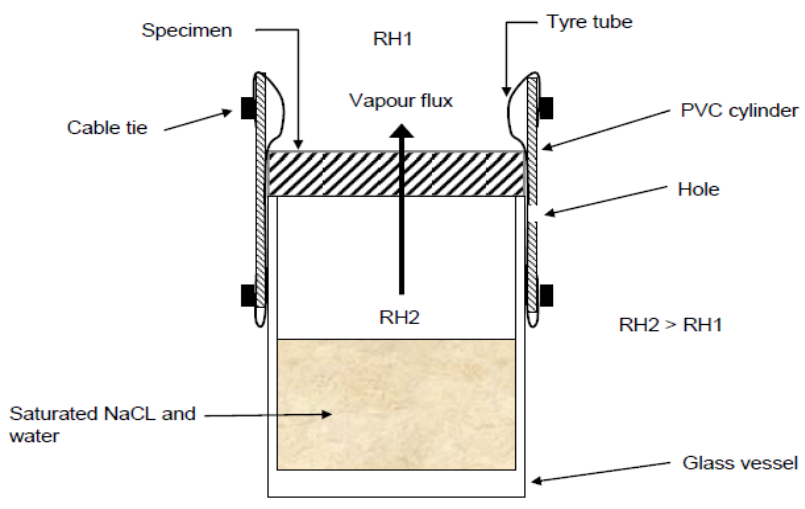

Figure 4:Vaporimeter based on the PVC-CHA system forwater-vapour diffusivity test, in the weight loss sequence (Redman et al. 2012).

As mentioned,before the experiment, wood samples were placed into the conditioning chamber to meet $14 \%$ moisture content.

The $19 \mathrm{~mm}$ and the $74 \mathrm{~mm}$ diameter cylindrical samples were placed onto similar diameter glass vessels containing a saturated solution of purified water and sodium chloride, ACS regent, $\geq 99,0 \%$ to measure the longitudinal and the transverse diffusivity respectively. A stable relative humidity (RH2) of $75 \%$ inside the vessel was produced from the saturated salt solution at $35^{\circ} \mathrm{C}$. To create an airtight seal around the sample and the vessel, a cylinder of PVC was used with an inserted piece of tyre tube clamped using cable ties (Figure 5). The installation of the device into the PVC pipe required the assistance of a vacuum pump to suck the tyre tube against the pipe wall while it was lowered over the sample and vessel. In the absence of the vacuum, the tyre tube relaxes tightly to the sample and vessel, creating an airtight seal.
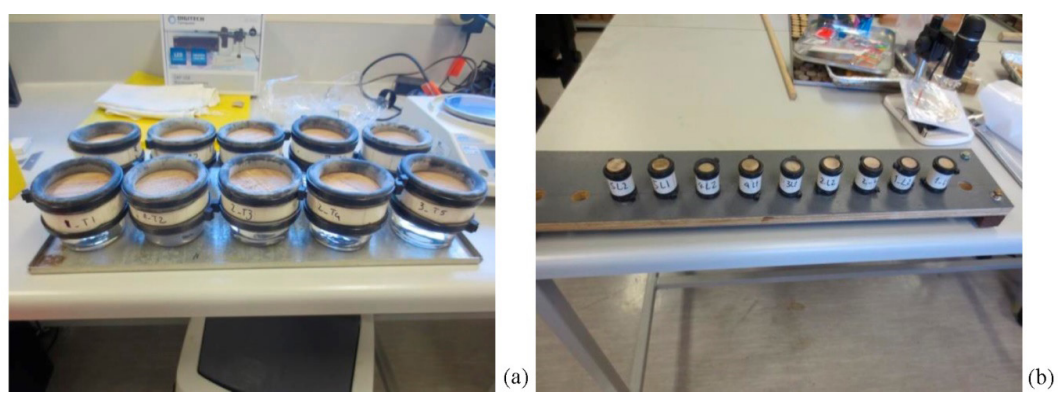

Figure 5: Photo of (a) Vaporimeter for transverse and (b) Longitudinal diffusivity test.

Aimingto create a vapour pressure gradient between two sides of the sample, the vaporimeter devices were placed in a constant environment chamber at $40 \%$ relative humidity (RH1) and $35^{\circ} \mathrm{C}$ temperature, that produced equilibrium conditions of $7 \%$ moisture content (Figure 6). This pressure gradient driving force created the diffusive flux through the sample during the measurement time. The diffusive flux was recognized by weighing the device periodically over time. 


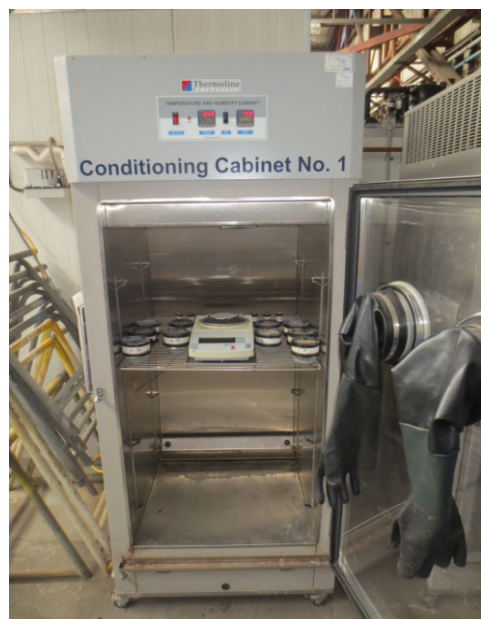

Figure 6: Photo of equipment to measure the mass flux in the steady-state regime.

The weight was carried out at the beginning of the measurement process but the mass flux of vapour (the overall weight loss) was only recognized when the decrease of mass was stable. A steady-state relationship was observed after a few days when the plot of the weight reduction as a function of time became a straight line.

By weighting the device inside the chamber via sealed glove gauntlets in the chamber door, and using a mass balance, accurate to $1 \mathrm{mg}$, placed inside the chamber (Figure 6), this experimental device allowed the mass flux to be measured with good stability of the conditions of temperature and relative humidity whatever the length of tests was.

The diffusion coefficient $\left(D_{b}\right)$ is then calculated from the following Equation 2 (Redman et al. 2012),

$$
D_{b}=\frac{m L}{t A G \rho_{w} \Delta X}
$$

In which

$D_{b}$ is the diffusion coefficient $\left(\mathrm{m}^{2} \cdot \mathrm{s}^{-1}\right)$

$m$ is the mass of transferred vapor $(\mathrm{kg})$

$L$ is the sample thickness (m)

$t$ is time (s)

$A$ is the sample area $\left(\mathrm{m}^{2}\right)$

$G$ is the specific gravity of the sample at moisture content $X . X$ is finalmoisture content of sample (\%)

$\rho_{w}$ is the density of water $\left(\mathrm{kg} \cdot \mathrm{m}^{-3}\right)$, considered as $1000 \mathrm{~kg} \cdot \mathrm{m}^{-3}$

$\Delta X=\left(X_{b}+X\right) / 2$ is the moisture content difference between the two parallel surfaces of the sample $\left(\mathrm{kg}^{\mathrm{kg}} \mathrm{kg}^{-1}\right)$; $X_{b}$ is the moisture content of the sample bottom $\left(\mathrm{kg}^{\mathrm{kg}} \mathrm{kg}^{-1}\right), X_{t}$ is the moisture content of the sample top $\left(\mathrm{kg}^{\mathrm{kg}} \mathrm{kg}^{-1}\right)$. 


\section{Statistical analysis}

The significant difference in permeability and diffusivity means between each pair of directions was assessed by one-way analysis of variance (ANOVA). Comparision procedures were carried out at a significance level (alpha) of 0,05. If the P-value in ANOVA results tablewas less than 0,05, the difference in these means was significant.

Standard deviation (SD) was performed and presented with mean of data in tables.

\section{RESULTS AND DISCUSSION}

\section{Permeability}

Gas and liquid permeability data for A. mangium in the longitudinal, radial, and tangential directions were presented in Table 1. The results highlighted the major difference between gas and liquid figures. The gas permeability was 4, 23, and 74 times higher than the liquid permeability in the longitudinal, radial, and tangential direction respectively.The difference between the gas and liquid permeability was smallest in the longitudinal direction, but it was significant because the p-value was 5,67x10-27, much less than 0,05 .These highly significant differences can be attributed to air being approximately 50 times less viscous than water at room temperature and the lower molecular size of air compared with water. Air is able to move through the small opening in wood tissue more easily than water. It is in agreement with the results obtained by Taghiyari (2012).

Table 1: Longitudinal (L), radial (R), and tangential (T) gas and liquid permeability (K) and anisotropy ratios for $A$. mangium.

\begin{tabular}{|c|c|c|c|c|c|c|c|c|c|}
\hline \multirow{3}{*}{ Type } & \multicolumn{6}{|c|}{$\mathrm{K}\left(\mathrm{m}^{2}\right)$} & \multicolumn{3}{|c|}{ Anisotropy Ratio } \\
\hline & \multicolumn{2}{|c|}{$\mathrm{L} \times 10^{-15}$} & \multicolumn{2}{|c|}{$\mathrm{R} \times 10^{-15}$} & \multicolumn{2}{|c|}{$\mathrm{T} \times 10^{-15}$} & \multirow{2}{*}{$K_{L} / K_{R}$} & \multirow{2}{*}{$K_{L} / K_{T}$} & \multirow{2}{*}{$K_{R} / K_{T}$} \\
\hline & Mean & SD & Mean & SD & Mean & SD & & & \\
\hline Gas & 2184,82 & 377,55 & 31,18 & 3,32 & 29,71 & 4,28 & 70,07 & 73,54 & 1,05 \\
\hline Liquid & 539,11 & 174,87 & 1,36 & 0,13 & 0,40 & 0,06 & 396,68 & 1338,35 & 3,37 \\
\hline
\end{tabular}

The results also showed the anisotropy ratios of both gas and liquid permeability. In previous studies, the longitudinal permeability can be over 1 million times greater than the transverse permeability for hardwoods (Agoua and Perré 2010, Redman et al. 2012). In this study, the longitudinal to tangential anisotropy ratio in liquid permeability was highest, but it was about over 1 thousand. The longitudinal to transverse anisotropy ratio in gas permeability was about 70 . Except for the insignificant difference in the gas permeability between the radial and tangential directions $(p=0,40)$, the differences in the gas and liquid permeability between the other directionswere highly significant (p-values were all from $10^{9}$ to $10^{12}$ times less than 0,05 ). The radial liquid permeability was 3,37 times higher than the tangential liquid permeability $\left(\mathrm{p}=2,91 \times 10^{-14}\right)$. This might be explained by the radial liquid flow is predominately through the ray, pit and cell wall capillary system, while the tangential liquid flow is more difficult to go through the pit structure (Hansmann et al.2002), where the bubbles are appeared to impede liquid flow. This phenomenon is also used to explain the differences in the radial and tangential diffusivity below. The high radial to tangential anisotropy ratio in liquid permeability is predicted to be one of the causes of drying defects for A. mangium.

Table 2 shows gas permeability for other hardwood species published by Agoua and Perré (2010) and Redman et al. (2012).Although their data were not results from parallel experiments with our experiments, they were obtained by tests using the same methods, on the same equipment system (ALU-CHA) and based on the same principle. All three measurement directions, longitudinal, radial and tangential, were performed in all of experiments. Using a mass flow meter to measure the airflux and calculatingthe permeability manually were differences in their studies compared to ours. However, this was not a big problem because the experiments were conducted in the elimination of equipment factors that could influence the results. $A$. mangium measured in this work was more permeable in all directions than the highest published figure shown 
in Table 2. This suggests the high permeability of A. mangium compared to other species reported partly relating to its fast drying rate at above fibre saturation point. The gas permeability anisotropy ratios were more modest in A. mangiumthan other species reported. This is probably due to the fact that the transverse pathways system (e.g. pits, rays) of $A$. mangium is more open.

Table 2: Longitudinal (L), radial (R), and tangential (T) gas permeability (K) and anisotropy ratios for other hardwood species.

\begin{tabular}{|c|c|c|c|c|c|c|}
\hline \multirow{2}{*}{ Species } & \multicolumn{3}{|c|}{$\mathrm{K}\left(\mathrm{m}^{2}\right)$} & \multicolumn{3}{|c|}{ Anisotropy Ratio } \\
\hline & $\mathrm{L} \times 10^{-15}$ & $\mathrm{R} \times 10^{-15}$ & $T \times 10^{-15}$ & $K_{L} / K_{R}$ & $K_{L} / K_{T}$ & $K_{R} / K_{T}$ \\
\hline $\begin{array}{c}\text { Spotted gum }^{\mathrm{b}} \\
(\text { Corymbiacitriodora Hook) }\end{array}$ & 0,4 & & 0,000003 & & 4750 & \\
\hline $\begin{array}{c}\text { Blackbutt }{ }^{\mathrm{b}}(\text { Eucalyptus } \\
\text { pilularis } \mathrm{Sm})\end{array}$ & 35,0 & 0,00001 & 0,00002 & 2440000 & 2305000 & 0,9 \\
\hline $\begin{array}{c}\text { Jarrah }^{\mathrm{b}} \\
\text { (Eucalyptus marginata D. } \\
\text { Don ex Sm.) }\end{array}$ & 67,4 & 0,00005 & 0,00004 & 3005000 & 1531000 & 1,1 \\
\hline $\begin{array}{l}\text { Messmate }^{\mathrm{b}} \text { (Eucalyptus } \\
\text { oblique L'Herit.) }\end{array}$ & 55,5 & 0,0086 & 0,0003 & 16400 & 3086000 & 177 \\
\hline $\operatorname{Beech}^{\mathrm{a}}($ Fagus sylvatica $)$ & 742 & 0,074 & 0,367 & 9970 & 2020 & 0,2 \\
\hline Teak $^{\mathrm{a}}$ (Tectona grandis) & 1750 & 0,00482 & 0,00569 & 363000 & 307000 & 0,8 \\
\hline
\end{tabular}

a (Agoua and Perré 2010); (Redman et al. 2012).

\section{Water-vapour diffusivity}

Figure 7 showed the evolution of the measured mass loss relating to the time in the transverse and longitudinal directions for $A$. mangium. To correct the effect of the sample geometry without being disturbed by the difference between the transverse and longitudinal sample diameters and the slight variation of sample thickness, the mass loss was divided by the sample cross-sectional area and multiplied by the sample thickness. For each test, the flux was computed from the linear part of the curves. The line chart described two distinctive groups of curves, one of small slopes and the other of extensively bigger slopes. The group of big sloped curves represented fluxes of water-vapour through samples in the longitudinal direction, and the group of small ones represented those through the radial and the tangential directions.

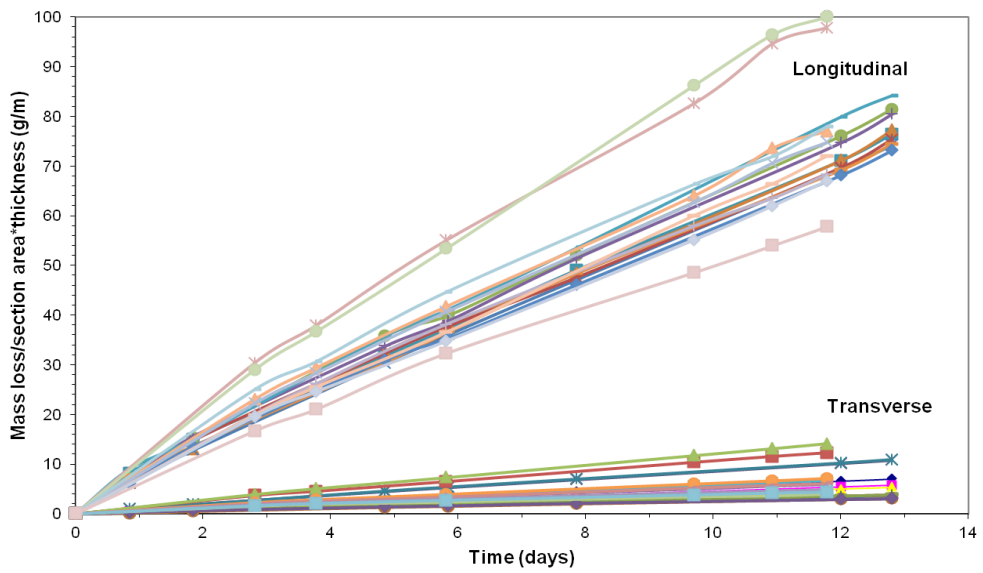

Figure 7: Evolution of the flux of bound water vapour over time in the $\mathrm{R}, \mathrm{T}$ and $\mathrm{L}$ directions for $A$. mangium.

The measured diffusion coefficients in the radial, tangential, and longitudinal directions for A. mangiumwere presented in Table 3. The difference in the diffusivity between each pair ofdirectionwere highly significant because $p$-values were all much less than 0,05 . The highest $p$-value was $7,3 \times 10^{-4}$. The obtaineddiffusion coefficients were in the range of $10^{-11} \mathrm{~m}^{2} \cdot \mathrm{s}^{-1}$ to $10^{-9} \mathrm{~m}^{2} \cdot \mathrm{s}^{-1}$ in the order of tangential, radial to longitudinal direction. The longitudinal to transverse anisotropy ratios of diffusivity which were in tens were much more modest than those of permeability. The radial diffusivity was 2,57 times higher than the tangential diffusivity. Similar to the permeability, the variation of ray, pit and cell wall capillary structures in the radial and tangential creating the difference in transverse diffusivity can also be a cause of drying defects for A. mangium. 
Table 3: Longitudinal (L), radial (R), and tangential (T) diffusion coefficients $\left(D_{b}\right)$ and anisotropy ratios for A. mangium.

\begin{tabular}{|l|l|l|l|l|l|l|l|l|}
\hline \multicolumn{5}{|c|}{$\mathrm{D}_{\mathrm{b}}\left(\mathrm{m}^{2} \mathrm{~s}^{-1}\right)$} & \multicolumn{3}{c|}{ Anisotropy Ratio } \\
\hline \multicolumn{2}{|c|}{$\mathrm{Lx} 10^{-10}$} & \multicolumn{2}{c|}{$\mathrm{Rx} 10^{-10}$} & \multicolumn{2}{c|}{$\mathrm{T} \times 10^{-10}$} & \multirow{2}{*}{$D_{b L} / D_{b R}$} & $D_{b L} / D_{b T}$ & $D_{b R} / D_{b T}$ \\
\cline { 1 - 5 } Mean & SD & Mean & SD & Mean & SD & & & \\
\hline 13,73 & 2,67 & 1,33 & 0,62 & 0,52 & 0,12 & 10,34 & 26,62 & 2,57 \\
\hline
\end{tabular}

The diffusion coefficients for other hardwood species published which were used to compare with $A$. mangium are shown in Table 4 (Agoua and Perré 2010, Redman et al. 2012). The numbers of all directions of diffusion coefficient for A. mangiumwere significantly higher than Australian hardwoods published by Redman et al. (2012), but markedly lower than two temperate hardwoods published by Agoua and Perré (2010). It is suggested that the drying rate from fibre saturation point of $A$. mangium can be faster than that of these Australian hardwoods, but slower than that of these temperate hardwoods. Besides, the higher radial to tangential diffusivity anisotropy ratio of $A$. mangiumcompounds its relatively easier drying defects at the late drying stage.

Table 4: Longitudinal (L), radial $(R)$, and tangential $(T)$ diffusion coefficients $\left(D_{b}\right)$ and anisotropy ratios for other hardwood specie.

\begin{tabular}{|c|c|c|c|c|c|c|}
\hline \multirow[b]{2}{*}{ Species } & \multicolumn{3}{|c|}{$D_{b}\left(m^{2} s^{-1}\right)$} & \multicolumn{3}{|c|}{ Anisotropy Ratio } \\
\hline & $\mathrm{Lx} 10^{-10}$ & $\operatorname{Rx} 10^{-10}$ & $\mathrm{Tx} 10^{-10}$ & $D_{b L} / D_{b R}$ & $D_{b L} / D_{b T}$ & $D_{b R} / D_{b T}$ \\
\hline $\begin{array}{c}\text { Spotted gum }^{\mathrm{b}} \\
\text { (Corymbia citriodora Hook) }\end{array}$ & 0,6 & 0,1 & 0,1 & 4,2 & 4,2 & 1,0 \\
\hline Blackbutt $^{\mathrm{b}}$ (Eucalyptus pilularis Sm) & 2,3 & 0,3 & 0,2 & 8,8 & 14,2 & 1,6 \\
\hline $\begin{array}{c}\text { Jarrah }^{\mathrm{b}} \text { (Eucalyptus marginata D.Don } \\
\text { ex Sm.) }\end{array}$ & 2,7 & 0,3 & 0,4 & 10,5 & 7,2 & 0,7 \\
\hline $\operatorname{Messmate}^{\mathrm{b}}$ (Eucalyptus obliqua L'Herit.) & 10,3 & 0,7 & 0,4 & 14,6 & 25,4 & 1,7 \\
\hline $\operatorname{Beech}^{\mathrm{a}}$ (Fagus sylvatica) & 86 & 4,8 & 2,1 & 18,1 & 40,6 & 2,25 \\
\hline Teak $^{\mathrm{a}}$ (Tectona grandis) & 40 & 2,8 & 1,7 & 14,1 & 23,7 & 1,68 \\
\hline
\end{tabular}

a (Agoua and Perré 2010); ' (Redman et al. 2012).

To summarize, results from this study suggested that the permeability and diffusivity of $A$. mangiumwere higher than other hardwoods published. By plotting permeability with diffusion coefficients, the demarcation between A. mangium and other materials were observed (Figure 8). Except for two temperate hardwoods reported by Agoua and Perré (2010), the A. mangium in both longitudinal and transverse directions were more permeable than all compared hardwoods and were more diffuse than the Australian hardwoods reported by Redman et al. (2012), which points out the fast and easy nature of removing water from A. mangium wood. 

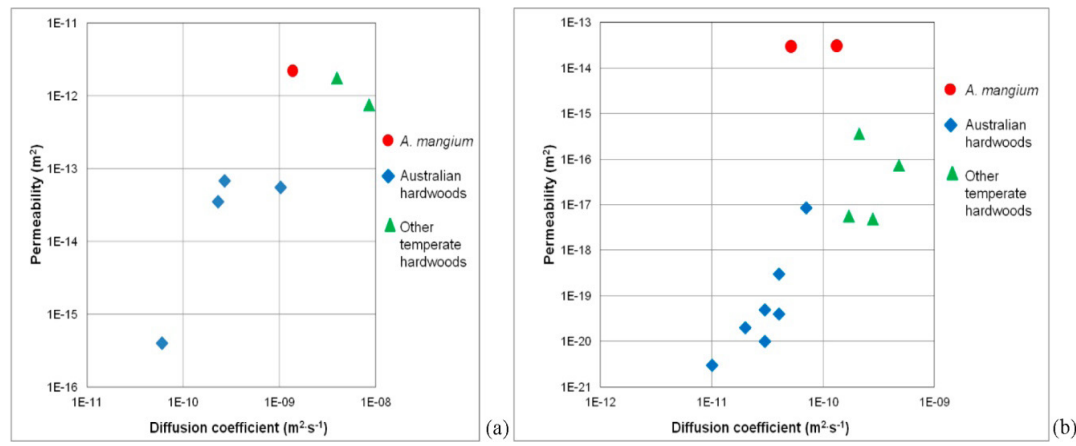

Figure 8: Comparison between permeability and diffusivity in the (a) longitudinal and (b) transverse directions for A. mangium and published hardwoods.

\section{CONCLUSIONS}

Characterization of mass transfer properties, gas and liquid permeability and diffusivity (in the steady-state regime) was achieved for $A$. mangium wood - a popular material supplying the wood industry in Vietnam. The results highlighted that:

The gas permeability was significantly higher than liquid permeability in each direction. This difference increased respectively from the longitudinal, radial, to tangential direction.

The permeability anisotropy ratios from longitudinal to transverse direction were not as so high as that of other species in previous reports. The radial to tangential anisotropy ratio was not significant in gas permeability, but quite high in liquid permeability.

The measured mass losses over time in the transverse and longitudinal directions were plotted. There was an obvious distinction between groups of sloped curves. The big group was the water-vapour loss through the longitudinal direction and the small one was that of transverse directions.

The longitudinal to transverse anisotropy ratios of diffusivity were much slighter than permeability. The difference between the radial and tangential diffusivity was significant, as same as for liquid permeability. This could be a cause of appearance of drying defects.

By obviousdemarcation on the mixed species graphs, the permeability and diffusivity in A. mangium were higher than other published hardwoods, which indicated a fast drying rate.

\section{ACKNOWLEDGMENTS}

The authors are grateful for the support of Research Institute of Forest Industries (RIFI) - Vietnamese Academy of Forest Sciences (VAFS) for the initial wood material collection; Salisbury Research Facility Center at the Department of Agriculture and Fisheries (DAF), Queensland, Australia is also acknowledged for assistance with labour and equipment. The authors thank to the Crawford Fund for the financial support of the training in relation to the activities of this study. 


\section{REFERENCES}

Agoua, E.; Perré, P. 2010. Mass transfer in wood: Identification of structural parameters fromdiffusivity and permeability measurements. J Porous Media 13(11): 1017-1024. http://doi.org/10.1615/JPorMedia.v13. i11.80

Booker, R.E. 1977. Problems in the measurement of longitudinal sapwood permeability and hydraulic conductivity. NZ J Forestry Sci 7(3): 297-306. http://www.scionresearch.com/_data/assets/pdf_file/0003/37479/ NZJFS731977BOOKER297-306.pdf

De Jong, W.; Sam, D.D.; Hung, T.V. 2006. Forest Rehabilitation in Vietnam Histories, realities and future. Center for International Forestry Research (CIFOR): Bogor, Indonesia. http://www.cifor.org/publications/pdf_files/Books/BDeJong0601.pdf

Hansmann, C.; Gindl, W.; Wimmer, R.; Teischinger, A. 2002. Permeability of wood - A review. Wood Res-Slovakia 47(4): 1-16. http://www.academia.edu/27225462/Permeability_of_wood_-_a_review.

Haque, M.N. 2002.Modelling of solar kilns and the development of an optimised schedule for drying hardwood timber. Ph.D. Thesis, University of Sydney. Sydney, Australia. http://ses.library.usyd.edu.au/handle/2123/581

Harwood, C.E.; Nambiar, S.E.K. 2014. Sustainable plantation forestry in South-East Asia. Australian Centre for International Agricultural Research (ACIAR): Canberra, Australia. http://aciar.gov.au/node/12221

Leggate, W.; Redman, A.L.; Wood, J.; Baillères, H.; Lee, D.J. 2019. Radial Permeability of the Hybrid Pine (Pinus elliottii $\times$ Pinus caribaea) in Australia. Bioresources 14(2): 4358-4372. http://bioresources.cnr. ncsu.edu/resources/radial-permeability-of-the-hybrid-pine-pinus-elliottii-x-pinus-caribaea-in-australia

Milota, M.R.; Tschernitz, J.L.; Verrill, S.P.; Mianowski, T. 1995. Gas permeability of plantation loblolly pine. Wood Fiber Sci 27(1): 34-40. http://wfs.swst.org/index.php/wfs/article/view/249

Perre, P.; Turner, Ian. 2007. Coupled Heat and Mass Transfer. In Perre, P (Ed.) Fundamentals of Wood Drying. Arbolor: France, p. 203-241. http://eprints.qut.edu.au/view/publication/Fundamentals_of_wood_drying.html.

Phonetip, K. 2018. Investigating optimized drying methods for Eucalyptus delegatensis using a solar kiln. Ph.D. Thesis, University of Melbourne. Melbourne, Australia. http://hdl.handle.net/11343/212529.

Redman, A.L.; Baillères, H.; Perré, P.; Carr, E.; Turner, I.W. 2017. A relevant and robust vacuum-drying model applied to hardwoods. Wood Sci Technol 51: 701-719. http://doi.org/10.1007/s00226-017-0908-7

Redman, A.L.; Baillères, H.; Turner, I.W.; Perré, P. 2012. Mass transfer properties (permeability and mass diffusivity) of four australian hardwood species. Bioresources 7(3): 3410-3424 http://ojs.cnr.ncsu.edu/ index.php/BioRes/article/view/BioRes_07_3_3410_Redman_Mass_Transfer_Properties_Australian_Hardwood

Taghiyari, H.R. 2012. Correlation between gas and liquid permeability in some nanosilver-impregnated and untreated hardwood. J Trop For Sci 24(2): 249-255. https://www.frim.gov.my/v1/JTFSOnline/jtfs/ v24n2/249-255.pdf

Tagne, M.S.; Rémond, R.; Rogaume, Y.; Zoulalian, A.; Perré, P. 2016. Characterization of sorption behavior and mass transfer properties of four central Africa tropical woods: Ayous, Sapele, Frake, Lotofa. Maderas-Cienc Tecnol 18(1): 207-226. http://doi.org/10.4067/s0718-221x2016005000020

Tuan, H.C. 2014. Announced the current status of national forest in 2013, M.o.A.a.R.D. (Decision no. 3322/QD-BNN-TCLN), MARD: Hanoi, Vietman. http://tongcuclamnghiep.gov.vn/Media/AuflaNews/Attachment/3322_Q\%C4\%90-BNN_TCLN.pdf

Tuan, H.C. 2020. Announced the current status of national forest in 2019, M.o.A.a.R.D. (Decision no. 1423/QD-BNN-TCLN), MARD: Hanoi, Vietman. http://tongcuclamnghiep.gov.vn/content/uploads/files/ Hie $\%$ CC\%A3\%CC\%82n\%20tra\%CC\%A3ng\%20ru\%CC\%9B\%CC\%80ng\%202019.pdf 
Yuniarti, K.; Brodie, G.; Ozarska, B.; Harris, G.; Waugh, G. 2018. A mathematical model for moisture movement during continous and intermittent drying of Eucalyptus saligna. EUR J Wood Wood Prod 76: 1165-1172. http://doi.org/10.1007/s00107-018-1296-x

Zohoun, S.; Agoua, E.; Degan, G.; Perré, P. 2003. An experimental correction proposed for an accurate determination of mass diffusivity of wood in steady regime. Heat Mass Transfer 39: 147-155. http://doi.org/10.1007/s00231-002-0324-9 